\title{
Internet use and well-being during the COVID-19 outbreak: Examining the role of gender, age, motives for using the internet and relational resources in an Italian adult sample.
}

\section{Claudia Venuleo}

University of Salento https://orcid.org/0000-0003-2500-1766

Claudia Marino ( $\square$ claudia.marino@unipd.it)

University of Padova https://orcid.org/0000-0002-1127-3907

Lucrezia Ferrante

University of Salento https://orcid.org/0000-0002-6623-4200

Simone Rollo

University of Salento https://orcid.org/0000-0001-7873-9348

Adriano Schimmenti

University of Enna "Kore" https://orcid.org/0000-0001-5181-2648

\section{Research Article}

Keywords: COVID-19, social distancing, loneliness, social support, problematic internet use, wellbeing

Posted Date: November 9th, 2020

DOI: https://doi.org/10.21203/rs.3.rs-104082/v1

License: (c) (1) This work is licensed under a Creative Commons Attribution 4.0 International License.

Read Full License 
Internet use and well-being during the COVID-19 outbreak: Examining the role of gender, age, motives for using the internet and relational resources in an Italian adult sample.

\begin{abstract}
The COVID-19 outbreak introduced self-isolation and social distancing as measures to reduce the spreading of the pandemic. As a consequence, internet usage has increased globally. The current study aims to show whether internet worked as a resource for well-being or as an amplifier of psychological distress and problematic internet use (PIU), considering the role of gender, age, motives for using the internet and online/offline relational resources.

Five hundred and seventy-three adult participants (M: 40.28; SD: 16.43; 64\% women) completed a form on sociodemographic characteristics and Internet use, and completed standardized measures on loneliness, online social support, well-being and PIU. A principal component analysis was computed to identify the main motives Internet use; ANOVA and Pearson's $r$ correlations were computed to examine (dis)similarities in motivational components with respect to gender, agegroup and psychosocial measures. A multivariate multiple regression analysis was performed to assess the contribution of the hypothesized predictors on overall well-being and PIU.

Three principal motives for Internet use were detected: leisure and social interaction, knowledge, learning/working. Significant differences were found among them with respect to gender and age group and online/offline relational resources. Differences were found in the likelihood of PIU and well-being related to all the variables considered, with the exception of online social support for PIU and gender and age for well-being.

These findings call for further research aimed to disentangle the correlates of PIU in a time of physical distancing, as well as for innovative efforts tailored to blunt the impacts of social isolation and bolster social connectivity.
\end{abstract}

Keywords: COVID-19, social distancing, loneliness, social support, problematic internet use, wellbeing

\title{
1 Introduction
}

The COVID-19 outbreak introduced self-isolation and social distancing globally, with the consequence of an increased internet usage (Wiederhold, 2020). Several scholars have emphasized the potential impact of COVID-19-related changes (such as disruption of face-to-face human connection, breakdown of habits, uncertainty about the future, financial insecurity, and loneliness) on people's psychological well-being (Liu et al. 2020; Sood 2020; Vijayaraghavan \& Singhal 2020). In this context, the massive use of the Internet can be a double-edged sword: on the one hand, access to technology has fostered people's well-being (e.g., through social media and working from home) and has facilitated the access to social support; on the other hand, it may have turned into problematic use, especially with regard to compulsive use and cognitive preoccupation.

The aim of the current study is to show whether internet worked as a resource for well-being or as an amplifier of psychological distress and problematic internet use (PIU). This question requires something more complex than a yes or a no answer; thus, what follows is a brief review of the literature about the different factors involved in fostering or obstructing people's well-being in the time of COVID-19.

\subsection{The multiple functions of Internet use during the COVID-19 pandemic}


Internet use may have represented for many people a significant resource to counteract physical distancing and isolation during quarantine measures, offering a means to communicate with others, maintaining networks of real friendship and facilitating support and interaction, providing entertainment and also health information (Nabi, Prestin, \& So 2013).

On the other hand, the large-scale entry of technology into our lives during lockdown measures and the psychological distress related to such measures are thought to have caused an increase in PIU. Previous studies had widely supported the positive relationship between psychosocial problems, such as low social support and loneliness, and greater problematic use of social media (Elhai, Levine, \& Hall 2020; Marino, Gini, Vieno, \& Spada 2018a, 2018b; Musetti, Corsano, Boursier, \& Schimmenti2020; Ruggieri, Santoro, Pace, Passanisi, \& Schimmenti 2020; Schimmenti \& Caretti 2017; Venuleo, Ferrante, \& Rollo 2020). This relationship is often explained through compensatory models, arguing that people can seek emotional relief through easily accessible means like internet devices, and over-reliance on such coping can lead to adverse consequences (Brand et al. 2019; Kardefelt-Winther 2014). It is likely that the COVID-19 pandemic and related measures of selfisolation and lockdown increased the tendency to engage in such behaviors in an excessive manner as putative coping strategies against anxiety, depression and loneliness (Király et al. 2020). However, the adaptive or maladaptive value of this coping mechanism on people's well-being during a pandemic needs to be explored in depth (Saltzman, Hansel, \& Bordnick 2020).

In recent days electronic and printed media have reported an increase in internet use over the past few months, globally, but we know very little about people's motives for using the internet during lockdown, nor if significant differences exist in the features of internet use related to sociodemographic characteristics during a pandemic, which previous studies (conducted before health emergency) have described (Andrisano-Ruggieri et al., 2016; Ang 2017; Baloglu, Şahin \& Arpaci 2020; Chen et al. 2017; Dufour et al. 2016; Fumero et al. 2018; Hunsaker \& Hargittai 2018; Weiser 2000). Several scholars had suggested that motives for internet use distinguish between unhealthy internet users or those who have problematic internet use behaviours, from healthy internet use (Marino et al. 2017; 2018). For instance, previous studies have found that the levels of problematic internet use of people who use the internet to entertain themselves and to establish social interaction are higher than that of those who use the internet primarily to obtain information (Caplan 2002; Ceyhan 2011). It is likely that also during the COVID-19 lockdown measures differences in the functions ascribed to information and communications technology (ICT) may have played a role in determining the negative or positive impact on well-being and PIU. To our knowledge, no studies have thoroughly explored the characteristics of internet use during the COVID-19 pandemic related to gender; with respect to age, contrasting remarks have been made. Few scholars have argued that older adults often opt to not use new technologies - only $49 \%$ of people aged 50 years and older use the internet according to a representative survey across 16 European countries (Köning \& Seifert 2018) - and this could lead to a double feeling of social exclusion in time of physical distancing (Armitage \& Nellums 2020; Seifert, 2020).Other scholars noted that greater internet use among the young also exposes them to misinformation about the disease, which can fuel fear and constitutes a risk for health (Bledsoe, Papa, \& Zimmermann 2020;Cuan-Baltazar et al. 2020; Schimmenti, Billieux, \& Starcevic 2020).

\subsection{Loneliness and social support during the COVID-19 pandemic}

Higher levels of psychological distress associated with the pandemic have been reported among the general population by recent studies (Huang \& Zhao 2020; Liu et al. 2020; Montemurro 2020). However, people's vulnerability to disruptive events is also shaped by the social and cultural resources readily available to people (Cannon \& Müller-Mahn 2010; Saltzman et al. 2020; Venuleo, Gelo, \& Salvatore 2020; Venuleo, Marinaci, Gennaro, \& Palmieri 2020). For instance, previous studies have shown that symptoms of depression and other serious mental illnesses following other 
pandemics (Lau et al. 2005; Mak et al. 2009) are exacerbated by loneliness and lack of social support (Wang et al. 2018). relationship between internet use and well-being during the lockdown measures is related to people's relational context, which might represent a source of psychological distress or on the contrary a material and symbolic resource to cope with life's circumstances, supporting well-being and reducing the possibility of developing PIU. Recent studies have suggested a relationship between social isolation and psychological distress during a pandemic (for a review, see: Loades et al. 2020) and prior research has indicated that higher loneliness (defined as a disagreeable or unacceptable lack of desired meaningful social relationships, Zammurer, 2008) and higher informal support and advice on the internet motivates people to use social media, also for excessive amounts of time (e.g. Kamin et al. 2019; Tang, Chen, Yang, Chung, \& Lee 2016). The health emergency may have exacerbated loneliness and the use of the internet as a way to compensate for this painful condition. If internet use reduced the feeling of loneliness and supported well-being by offering online social support, or on the other hand exacerbated pain and an unhealthy commitment on the internet is a question left unexplored. Previous studies suggested that online and offline social resources relate to higher well-being (Chu, Saucier, \& Hafner 2010; Goswamiet al. 2020) but have a different impact on PIU. For example, Wang and Wang (2013) found that online support is positively associated with PIU, whereas offline social support has a negative relationship. A more complex relationship is suggested by the "social compensation vs enhancement hypothesis" (Zywica\& Danowski 2008): accordingly, the outcomes of online social support on the users are either positive or negative depending on the strength of the user's perception of support in offline life. That is, if seeking online social support is meant to compensate for weak offline social networks, the user will tend to develop a problematic use of the internet. Grieve and colleagues'(2013) findings support this perspective: in their study on a large sample of Australian adults, in whom the effect of online social support in determining PIU and well-being was moderated by their offline social support. These studies suggest that offline and online social resources must be simultaneously taken into account in investigating their effects on PIU and wellbeing.

\subsection{Aims}

Considering these considerations, the study pursues two main goals:

(a) First, to explore the relationships between socio-demographic characteristics (age and gender) and people's motives for using the internet during the COVID-19 pandemic. Consistently with previous literature, and due the different challenges faced during the pandemic related to age and gender, we expect to find significant differences in Internet motives related to socio-demographic characteristics;

(b) Second, to examine the relative contribution of a) gender and age; b) internet use motives and c) online and offline relational resources (online social support and loneliness) on overall well-being and PIU, taking into account the association between these outcome variables. We expect that these potential predictors have an impact on health outcomes. Especially, it is likely that the greater the loneliness (thus the lower the offline relational resources), the lower the well-being and the higher the likelihood of PIU. With respect to online social support, we expect that it may increase wellbeing, acting as a resource to respond to the relational needs in the time of lockdown measures. A complex relationship is supposed to exist between online support and PIU: high support may increase the chance of a problematic internet use in the context of a high loneliness level; the opposite if the feeling is that of not being lonely. Finally, a significant negative relationship was expected between PIU and well-being. 


\section{Method \\ 2.1 Participants and Procedures}

An anonymous online survey was available online from 4th to the 24th May 2020, the period when the Italian government imposed self-isolation with the "Chiudi Italia" decree. The protocol was disseminated through social networks.

A total of 600 questionnaires were collected; 573 were completed and were used for the study (M: 40.28; SD: 16.43; women: 64\%; aged 18-25: 30.2\%; aged 26-35: 18.8\%; aged 36-45: 9.8\%; over 45: $41.2 \%$ ). With regard to Internet use, $72.7 \%$ the participants report having used social networking sites "quite a lot" or "a lot" (in a four point Likert scale from not at all to a lot), 78\% videocall platforms (e.g. WhatsApp, Skype and other platforms), and 67.6\% streaming services.

All procedures performed in the study were in accordance with the ethical standards of the institutional research committee and with the 1964 Helsinki declaration and its later amendments or comparable ethical standards. According to the ethical code of the Italian Psychology Association (AIP) (http://www.aipass.org/node/26 ) and the Italian Code concerning the protection of personal data (Legislative decree No 101/2018), participants were informed about the general aim of the research, the anonymity of responses and the voluntary nature of participation and signed an informed consent form. No incentive was given. The project was approved by the Ethics Commission for Research in Psychology of the [blinded for review] (protocol n. [blinded for review]).

\subsection{Measures}

Application and devices for Internet use. Internet activities were assessed using a 4-point Likert scale from " $1=$ Not at all" to " $4=\mathrm{A}$ lot". The items consisted of 3 statements referring to the following use of Internet: social networking sites; streaming services; videochat/videocall. An example item is: "In the last two weeks, how much have you used Social Network sites (Facebook, Instagram, SnapChat, etc.)?".

Internet use motives. Seven ad hoc items were used to detect the functions of Internet use in the past two weeks. The items were derived from extant research on uses and motivations for internet use which have widely recognised such core motivations as getting information, being entertained/leisure, interacting with others socially (establishing and maintaining contact with others), learning and self-reactive outcomes (such as relieving boredom) (Bozoglan et al. 2014; Flanagin \& Metzger 2001; LaRose \& Eastin 2004; Papacharissi \& Mendelson 2010). The items consist of 7 statements referring to the following reasons for Internet use: work/study; keeping in touch with loved ones (family, friends); acquiring information about the covid-19 emergency; cultural entertainment; escaping from reality; satisfying interpersonal and social needs; having fun/spending time. An example item is: "In the last two weeks, how much have you used the Internet for work/study?". Respondents were asked to use a 4-point Likert scale to evaluate the use of the Internet for each function. from " $1=$ Not at all" to " $4=\mathrm{A}$ lot".

Perceived loneliness. Subjective loneliness was measured using the General Loneliness Sub-scale from the Italian Loneliness Sub-scale (ILS; Zammuner 2008). ILS General Loneliness comprises 7 items measuring subjective perceptions of both social and emotional loneliness. Participants were asked to rate the degree to which they feel every statement in "the past two weeks" on a four-point Likert scale (from "I often feel this way" to "I never feel this way"). An example item is: "I lack 
companionship". A high score indicates a high level of subjective loneliness. A good internal consistency was found in the current study (Cronbach's $\alpha=.80$ ).

Online support. The questionnaire for the Evaluation of Social Support (SS) (Poortinga 2006) was adapted to measure the perception of social support received online. The instrument consists of 7 statements related to online relationships and their capacity to make feel you good and to give encouragement. Each item is rated on a 3-point scale: 1="not true", $2=$ "partly true", and $3=$ "certainly true". An example item is: "Online there are people I know who can be relied on no matter what happens". A good internal consistency was found in the current study (Cronbach's $\alpha=$ $.90)$.

Overall well-being. The Italian version (Di Fabio 2016) of the Flourishing Scale (FS; Diener, et al., 2010 ) by was used to evaluate general wellbeing. The FS encompasses items regarding human flourishing in relevant areas such as: purpose in life; relationships; self-esteem; feelings of competence, and optimism andconsists of eight items with response options rated on a 6-point Likert scale ranging from 1 (Strongly disagree) to 7 (Strongly agree). An example item is: "my social relationships are supportive and rewarding". Participants were asked to think to the past two weeks while answering. The FS showed a good reliability in the present study (Cronbach's $\alpha=.88$ ).

Problematic internet use. The 5-item version of the recently developed and cross-nationally validated Compulsive Internet Use Scale (CIUS; Lopez-Fernandez et al. 2019) was used for the measure of PIU. All items are scored on a 5-point Likert scale from 0 (never) to 4 (very often). Items capture the main aspects of online problematic behaviours, namely loss of control, preoccupation regarding Internet use, withdrawal symptoms, coping/mood modification, and conflict. Validated in eight languages, included Italian, the 5-item CIU is recognized as one of the best psychometric instruments assessing PIU in terms of its psychometric properties and consistency of findings across different sample (Lopez-Fernandez et al. 2019). An example item is: "Do you find it difficult to stop using the Internet when you are online?". A good internal consistency was found in the current study (Cronbach's $\alpha=.76$ ).

\subsection{Data Analyses}

The statistical analyses were performed in three steps.

First, as a preliminary step, a principal component analysis (PCA) was applied to the ratings of the Internet use motives to identify a few variables (formative factors) that can summarise the covariance among the indicators (Coltmanet al. 2008). The solution of PCA was rotated using Varimax rotation. The participants' factorial scores on the components extracted by PCA were used as a measurement of their Internet pattern of use.

Second, ANOVA and Pearson's $r$ correlations were computed to test similarities and dissimilarities in the Internet motivational components with respect to gender and ageclass, as well as to the psychosocial measures of loneliness and online support.

Third, a multivariate multiple regression model was performed to assess the contribution of the hypothesized predictors (i.e. demographic characteristics, internet use motives, perceived online social support and loneliness) on the two dependent variables (i.e. overall well-being and PIU). The Lavaan package (Rosseel 2012) of the software R (R Development Core Team 2012) and the Maximum Likelihood estimator were used. To evaluate the goodness of fit of the model we considered the $R^{2}$ of each dependent variable and the total coefficient of determination (TCD; Bollen 1989; Jöreskog \& Sörbom 1996). 


\section{Results}

\subsection{Internet use motives}

The scree plot of PCA applied to the internet motives indicated a three-component solution (Table 1 ) as a good choice (variance explained $=64 \%$ ). Variables loading heavily on the first component (34.2\% of the variance) were to have fun/to spend time, to escape from reality, to satisfy interpersonal and social needs, and to maintain connections with the loved ones; this component was labelled "Leisure and social interaction purposes". Variables loading heavily on the second component (16.37\% of the variance) were to acquire information on the COVID-19 health emergency and to have cultural entertainment; this component was labelled "Knowledge purposes". Finally, only one item load significantly on the third component (13.34\% of the variance) which was labelled "Learning/working purposes". The three factors seem to be consistent with the core motivations found by previous studies on uses and gratifications of media (Flanagin, \& Metzger 2001; LaRose \& Eastin 2004). For instance, Flanagin and Metzger (2001) identified leisure and relationship purpose, informational purpose and learning. The standardized scores of the subjects on the three components were used for the subsequent analysis.

[TABLE 1 insert here]

\section{2 (Dis)similarities of Internet use motives for gender and age}

Significant differences were found with respect to gender and age-class on the mean scores of the three motives (i.e. leisure and social interaction, knowledge purposes, learning/working purposes), with women scoring higher than men; the classes 18-25 and 26-35 years scoring higher on "leisure and social interaction purposes" than the older, the classes 36-45 scoring higher on "knowledge purposes" and "learning/working" purposes than the other group (Table 2).

[TABLE 2 insert here]

\subsection{Relation between internet motivational components and relational resources}

Results from Pearson's $r$ correlations between relational resources measures and internet use motives (table 3) show that the higher the loneliness level, the greater the use of internet for leisure and interactional purposes, and the higher the online social support, the greater the use of internet for all the three motivational components identified.

[TABLE 3 insert here]

\subsection{The impact of demographic characteristics, loneliness and online social support on measures of well-being and problematic internet use}

Results of the multivariate multiple regression (figure 1) show that gender and age do not have an impact on well-being, but they affect PIU; particularly women, compared to men, and the young, compared to the elderly, are more likely to report higher levels of PIU. Internet function components affect the outcome measures differently: the use of the internet for "knowledge" and "learning/working" purposes positively predicts well-being but not PIU; the use of internet for "leisure and social interaction" purposes predicts PIU but not well-being. Loneliness is shown to 
affect both well-being and PIU: the higher the loneliness level, the lower the well-being and the higher the levels of PIU. Online social support affects well-being (the higher the online support, the greater the well-being) but not PIU. A significant negative relationship was also found between well-being and PIU $(-0.15 ; p<.001)$. The model accounts for $27.8 \%$ of the variance of well-being, and for the $28.6 \%$ of variance of PIU. Finally, the total amount variance explained by the model and indicated by the Total Coefficient of Determination $(\mathrm{TCD}=0.46)$ shows a good fit to the observed data.

[FIGURE 1 insert here]

\section{Discussion}

The study has deepened our knowledge of people's motivations for using the internet during the COVID-19 pandemic, their relationships with the online and offline relational resources and the impact of these on overall well-being and PIU.

Findings are consistent with previous studies, which have shown a negative effect of increased age on Internet use, in terms of time spent online, frequency, or variety of usage (Blank \& Groselj 2014; Pearce \& Rice 2013; Van Deursen \& Van Dijk 2014). The findings also show that younger people more frequently engage with all usage types. The study of Büchi and colleagues (2016), based on cross-country comparisons, offered support to our findings and showed that social interaction and entertainment are particularly dependent on age. Gruber and colleagues (2020) noted that emerging adulthood may represent a developmental stage with unique challenges imposed by COVID-19, such as disrupted social roles as a result of missing important experiences and returning to living with parents. So, it is understandable that the urge to use the internet to maintain social interaction was higher for the younger age-group than for the older groups. Different factors may explain the increased use of internet for knowledge purposes among people aged 36-45, included closer proximity to their loved ones, which may have made the need to use the internet for leisure and social interaction purposes less intense, and the higher awareness of the severity of the health emergency. In the context of previous pandemics, the perceived severity of the situation has been shown to increase information sharing (Huang et al. 2015).

With respect to gender, previous reviews on technology use found significant differences in the patterns of ICT use among men and women (e.g., Ang, 2017; Goswami \& Dutta, 2015; Krasnova et al., 2017; Venkatesh, Thong, \& Xu, 2012). For example, some studies have suggested that women are mainly driven by relational uses, such as maintaining close ties and getting access to social information on close and distant networks and to health-related information, whereas men base their continuance intentions on their ability to gain information of a general nature (Bidmon \& Terlutter, 2015; Krasnova et al., 2017; Lim \& Kumar, 2019; Lupton \& Maslen, 2019). Our findings suggest a more differentiated use of internet among women during lockdown measures: they were found to have used internet more than men for all three function components, expressing not only relational purposes but also the goals of knowledge (not limited to the health emergency but extended to cultural resources available in the internet) and learning/working purposes. Multiple factors may explain this extensive use of internet among women. Some scholars have indeed suggested that inequality in the employment situation and in the distribution of activities related to family management and children's care could have amplified women's multitasking agenda(Hutt, 2020; Rinaldi, 2020) and thus the importance of being able to do any activity at any time, such as finding information and engaging in entertainment activities directly at home (Bidmon \& Terlutter, 2015).

Do different patterns of usage relate to people's relational resources? Our findings show that people using internet for leisure and interactional motives are characterized by higher levels of loneliness and higher online social support. In this respect, it seems that internet has provided these individuals with a potential answer to their relational needs which remained unsatisfied in their offline context. The findings are consistent with the compensatory model of PIU, which suggests 
that people who feel "left out" may go online in order to compensate for their lack of offline social relationships (Kardefelt-Winther2014; Király et al. 2020). People using internet for "knowledge purposes" and for "learning/working purposes" do not describe themselves as having high or low levels of loneliness but tend to express higher levels of online social support. Thus, online social support seems to be associated to internet use whatever the motive for surfing the net. The findings are consistent with the proposal to differentiate the role of the offline and online relational resources in examining people's involvement with the internet (Grieve et al. 2013; Wang \& Wang 2013). Considering the specific circumstances, that is, the COVID-19 lockdown measures, the findings suggest that Internet was felt to be a crucial kind of support, regardless of the motives for using it. Given the sudden breakdown of daily routine and habits imposed by the health emergency throughout various domains of life, it is understandable that the very possibility of maintaining online social contact, leisure, cultural entertainment, working and studying took on the sense of offering a supportive resource.

What is the effect on overall well-being and PIU of the selected potential predictors (i.e. gender, age, internet use motives, loneliness, online social support)? Multivariate multiple regression analysis showed differences in the likelihood of PIU in relation to all the variables considered, with the exception of online social support. Specifically, being a younger woman, using internet for "leisure and social interaction" purposes and suffering from loneliness were shown to be predictors for PIU.

The association between younger age and PIU is consistent with previous studies (Kuss\& LopezFernandez, 2016). The same consideration applies to the impact of leisure and social purposes on PIU (e.g. Kircaburun et al., 2018; Li \& Chung, 2006). For example, Kircaburun and colleagues (2018) found that higher levels of internet use for social reasons (i.e. meeting new people and socializing) and entertainment were associated with problematic social media use among university students. The recent study of Gao and colleagues during the COVID-19 pandemic (2020) reported that leisure-time internet use, but not work-time internet use, was positively associated with PIU. Accordingly, the increased use of the Internet during the lockdown measures did not mean a higher risk of PIU but favored this risk when the Internet was the only way to achieve leisure and social purposes.

With regard to gender, previous reviews on technology use reported mixed results (for a review: Baloglu, Şahin \& Arpaci 2020). Several studies reported gender differences, with a wealth of research reporting that men are more vulnerable to PIU and to severe symptoms of it compared to women (El Asam, Samara, \& Terry 2019; Fumero et al. 2018; Kanan et al. 2019; Yu et al. 2018; Wartberg, Zieglmeier, \& Kammerl 2020). However, another group study came to the opposite conclusion, finding higher PIU severity among women (Casaló \& Escario 2019; Karaer \& Akdemir 2019; Laconi et al. 2018), consistently with our findings. It is possible that these different findings are related to different study samples and different types of Internet use examined (e.g., games, social networks, e-commerce sites). However, it must be stressed that the importance of micropolitics, families, social and cultural capital in an individual's internet acquisition and use should not be overlooked. As already suggested in the relevant literature (Anderson \& Tracey 2001; Selwyn et al. 2005) - it is not being a women per se which makes a problematic internet user or non-user, but the opportunities, needs, motivations, material circumstances and lived experiences of being a woman which all amount to such involvement.

Concerning the relationship between loneliness and PIU, previous studies have already recognised the positive association between them (Caplan 2006; Holt-Lunstad et al. 2015; Yao \& Zhong 2014; Zhang et al. 2018), although competing hypotheses have been suggested: the displacement hypothesis proposes that heavy Internet use increases loneliness, isolating people from face-to-face interactions with others (Mohseni et al. 2008; Nie 2001); conversely, other scholars suggest that lonely people are more likely to be attracted to Internet use (Demir \& Kutlu 2016; Song et al. 2014; Sharifpoor et al. 2017), consistently with clinical reports and several influential theoretical 
models (e.g., self-medication model, see Schimmenti \& Caretti, 2010, 2017; Schimmenti et al., 2012, for an application of the model on PIU) that underline the important role played by Finally, a third view proposes that the association between loneliness and PIU has to be conceived as bidirectional (Tian et al. 2017; Zhang et al. 2018) and dynamic (Nowland, Necka, \& Cacioppo 2018), depending on the reasons for internet use. Our findings show that only the component of "leisure and social interaction motives" is associated to greater loneliness and has a critical impact on PIU. The specific circumstances of the current study - the lockdown measures related to the COVID-19 health emergency - may have contributed to identify leisure and social purposes as a way to escape from reality: a reality felt by a large part of the population as a source of fear and distress (Schimmenti et al., 2020).

With respect to overall well-being, multivariate regression did not prove the impact of gender and age-related differences. However, a significant impact of the use of internet for "knowledge" and "learning/working" purposes, loneliness and online social support was found.

It is worth noting that loneliness can be recognized as a common risk factor for PIU and well-being, supporting the idea that relational resources played a crucial role during lockdown measures both in protecting people from psychological distress and in influencing the possibility that internet worked as a resource or amplifier of clinical symptoms.

Finally, the fact that well-being and PIU proved to be associated is consistent with the previous literature (Muusses et al. 2014; Schimmenti et al. 2012), which has widely recognized the relationship between PIU and well-being. Although the debate regarding the directionality of this association remains open, a few longitudinal studies suggested that PIU and well-being mutually reinforce each other, in that lower wellbeing influences internet escapism, which increases the likelihood of PIU, which in turn may decrease wellbeing even further, leading to harmful consequences (Ohno 2016; Van den Eijnden et al. 2008; Vidal et al. 2020). Consistently with the view of a circular linkage, we tend to hypothesize that in the context of lockdown measures related to the COVID-19 health emergency, which reduced offline social contacts and had a recognized negative impact on psychological well-being, poor well-being increased the likelihood of PIU which, in turn, worsened the wellbeing.

\section{Limitations}

The present results are preliminary, and some limitations needed be acknowledged. First, the nonrandomly selected sample and the use of self-reported data may be influenced by recall bias and answer accuracy. Second, the cross-sectional design of the study does not allow definitive statements about causality. Third, further studies are needed to investigate the role of other important factors in mediating the effect of the target variables on people's well-being and PIU: individual risk factors, such as anxiety and depression as recognized correlates of lockdown measures, and subjective and contextual aspects, such as the meaning through which people have interpreted the health emergency, the different life situations and the related specific challenges imposed by the pandemic.

\section{Conclusions}

Our findings support the view that some of the pandemic-related circumstances, such as physical distancing and increased internet usage, have an impact on people's well-being depending on the relational resources available to them to cope with the situation. It is not new, but a sign that the psychological features of health emergency need to be considered deeply. Social disconnectedness, perceived isolation and lack of social support have constantly been found to present distinct associations with mental health (de Jong Gierveld, van Tilburg, \& Dykstra 2018). However, these 
kinds of considerations have found little space in the debate on the impact of the pandemic. On the one hand, the institutional responses put in place to protect citizens have mostly interpreted health in biological terms, marginalising the psychological aspect of well-being; on the other hand the overriding focus of the scholars in the field of human and social sciences on the negative effects of the health emergency overshadowed the many variations in the experience of quarantine due to contextual aspects related to the micro-sphere (such as with whom one lives and the quality of the relationship), as well as the macro social sphere (e.g. the institutional responses put into place to respond to the health emergency and to support citizens).

As clinical implications, our findings highlight the critical role of relational resources in reducing the risk of PIU and improving individual well-being. This suggests that preventing psychological disorders and PIU in a time of physical distancing requires an in-depth consideration of the networks where people live, which may provide the conditions and instruments todeal with problems in life and use the Internet in a healthy manner.Innovative and effective efforts to blunt the impacts of social isolation and bolster social connectivity are more critical than ever before. Pivotal initiatives to increase distal connectivity during the current pandemic are documented (Smith, Steinman, \& Casey 2020). For example, many organizations are using telephone reassurance and efforts to encourage involvement, which include having community health workers, social workers, clinicians, and other personnel make telephone calls to vulnerable groups in order to check on their general well-being and identify needs, offer an opportunity for socializing, and link them to available services and resources. Capitalizing on existing research and practices in the field, clinicians and health/social services can contribute to the effort of mitigating the risk of social isolation when physical distancing is needed to ensurepeople's safety.

\section{References}

Anderson, B., \& Tracey, K. (2001). Digital Living: The Impact (or Otherwise) of the Internet on Everyday Life. American Behavioral Scientist, 45(3), 456-75. https://doi.org/10.1177/00027640121957295

Andrisano, R., Santoro, E., De Caro, F., Palmieri, L., Capunzo, M., Venuleo, C., \& Boccia, G. (2016). Internet addiction: A prevention action-research intervention. Epidemiology, Biostatistics and Public Health, 13(4), e11817-1- e11817-5. https://doi.org/10.2427/11817

Ang, C. S. (2017). Internet habit strength and online communication: Exploring gender differences. Computers Human Behavior, 66, 1-6. https://doi.org/10.1016/j.chb.2016.09.028

Armitage, R., \&Nellums, L. B. (2020). COVID-19 and the consequences of isolating the elderly. The Lancet Public Health, 5(5), e256. https://doi.org/10.1016/S2468-2667(20)30061$\underline{X}$

Baloğlu, M., Şahin, R., \&Arpaci, I. (2020). A Review of Recent Research in Problematic Internet Use: Gender and Cultural Differences. Current Opinion in Psychology, 36, 124-129. https://doi.org/10.1016/j.copsyc.2020.05.008

Bidmon, S., \&Terlutter, R. (2015). Gender differences in searching for health information on the internet and the virtual patient-physician relationship in Germany: exploratory results on how men and women differ and why. Journal of medical Internet research, 17(6), e156. https://doi.org/10.2196/jmir.4127

Blank, G., \&Groselj, D. (2014). Dimensions of Internet use: amount, variety, and types. Information. Communication \& Society, 17(4), 417-435. https://doi.org/10.1080/1369118X.2014.889189

Bollen, K. A. (1989). Structural equations with latent variables. New York: Wiley. 
Bozoglan, B., Demirer, V., \&Sahin, I. (2014). Problematic Internet use: Functions of use, cognitive absorption, and depression. Computers in Human Behavior, 37, 117123.https://doi.org/10.1016/j.chb.2014.04.042

Brand, M., Wegmann, E., Stark, R., Müller, A., Wölfling, K., Robbins, T. W., \& Potenza, M. N. (2019). The Interaction of Person-Affect-Cognition-Execution (I-PACE) model for addictive behaviors: Update, generalization to addictive behaviors beyond internet-use disorders, and specification of the process character of addictive behaviors. Neuroscience \&Biobehavioral Reviews, 104, 1-10. https://doi.org/10.1016/j.neubiorev.2019.06.032

Büchi, M., Just, N., \&Latzer, M. (2016). Modeling the second-level digital divide: A five-country study of social differences in Internet use. New media \& society, 18(11), 2703-2722. https://doi.org/10.1177/1461444815604154

Cannon, T., \& Müller-Mahn, D. (2010). Vulnerability, resilience and development discourses in context of climate change. Natural hazards, 55(3), 621-635.https://doi.org/10.1007/s11069010-9499-4.

Caplan, S. E. (2002). Problematic Internet use and psychological wellbeing: development of a theory-based cognitive-behavioral measurement instrument. Computers in Human Behavior, 18, 553-75. https://doi.org/10.1016/S0747-5632(02)00004-3

Caplan, S. E. (2006). Relations among loneliness, social anxiety, and problematic Internet use. CyberPsychology\&behavior, 10(2), 234-242. https://doi.org/10.1089/cpb.2006.9963

Casaló, L. V., \&Escario, J. J. (2019). Predictors of excessive internet use among adolescents in Spain: The relevance of the relationship between parents and their children. Computers in Human Behavior, 92, 344-351. https://doi.org/10.1016/j.chb.2018.11.042

Ceyhan, A. A. (2011). University Students' Problematic Internet Use and Communication Skills According to the Internet Use Purposes. Educational Sciences: Theory and Practice, 11(1), 69-77.

Chen, C., Zhang, K. Z., Gong, X., Zhao, S. J., Lee, M. K., \& Liang, L. (2017). Examining the effects of motives and gender differences on smartphone addiction. Computers in Human Behavior, 75, 891-902. https://doi.org/10.1016/j.chb.2017.07.002

Chu, P. S., Saucier, D. A., \& Hafner, E. (2010). Meta-analysis of the relationships between social support and well-being in children and adolescents. Journal of social and clinical psychology, 29(6), 624-645. https://doi.org/10.1521/jscp.2010.29.6.624

Coltman T., Devinney T.M., Midgley D.F., and Venaik S. (2008). Formative versus reflective measurement models: Two applications of formative measurement. Journal of Business Research, 61, 1250-1262. https://doi.org/10.1016/j.jbusres.2008.01.013

Cuan-Baltazar, J. Y., Muñoz-Perez, M. J., Robledo-Vega, C., Pérez-Zepeda, M. F., \& Soto-Vega, E. (2020). Misinformation of COVID-19 on the internet: infodemiology study. JMIR public health and surveillance, 6(2), e18444. https://doi.org/10.2196/18444

de Jong-Gierveld, J., van Tilburg, T. G., Dykstra, P. A. (2018). New ways of theorizing and conducting research in the field of loneliness and social isolation. In A. L. Vangelisti\& D. Perlman (Eds.) The Cambridge handbook of personal relationships. Cambridge: Cambridge University Press (pp. 391-404).

Demir, Y., and Kutlu, M. (2016). The relationship between loneliness and depression: mediation role of internet addiction. Educ. Process 5, 97-105. https://doi.org/10.12973/edupij.2016.52.1

Di Fabio, A. (2016). Flourishing Scale: Primo contributoallavalidazionedellaversioneitaliana [Flourishing Scale: First contribution to the validation of the Italian version]. Counsel. Giornale Ital. Ric. Appl, 9(10.14605).

Diener, E., Wirtz, D., Tov, W., Kim-Prieto, C., Choi, D. W., Oishi, S., \& Biswas-Diener, R. (2010). New well-being measures: Short scales to assess flourishing and positive and negative feelings. Social indicators research, 97(2), 143-156. https://doi.org/10.1007/s11205-009$\underline{9493-\mathrm{y}}$ 
Dufour, M., Brunelle, N., Tremblay, J., Leclerc, D., Cousineau, M. M., Khazaal, Y., ... \&Berbiche, D. (2016). Gender difference in internet use and internet problems among Quebec high school https://doi.org/10.1177/0706743716640755 
Hutt, R. (2020). The coronavirus fallout may be worse for women than men. Here 's why. World Economic forum Covid Action Platform. Retrieved 10th of July, 2020 fromhttps://www.weforum.org/agenda/2020/03/the-coronavirus-fallout-may-be-worse-forwomen-than-men-heres-why/

Indian, M., \& Grieve, R. (2014). When Facebook is easier than face-to-face: Social support derived from Facebook in socially anxious individuals. Personality and Individual Differences, 59, 102-106.https://doi.org/10.1016/j.paid.2013.11.016

Jöreskog, K. G. \&Sörbom, D. (1996). LISREL 8: User's reference guide. Chicago: Scientific Software International.

Kamin, S. T., Beyer, A., and Lang, F. R. (2019). Social support is associated with technology use in old age. Z. Gerontol. Geriatr., 53, 256-262. https://doi.org/10.1007/s00391-019-01529-Z

Kannan, B., Karthik, S., Pal, G. K., \& Menon, V. (2019). Gender Variation in the Prevalence of Internet Addiction and Impact of Internet Addiction on Reaction Time and Heart Rate Variability in Medical College Students. Journal of Clinical \& Diagnostic Research, 13(4), 14.

Karaer, Y., \&Akdemir, D. (2019). Parenting styles, perceived social support and emotion regulation in adolescents with internet addiction. Comprehensive psychiatry, 92, 22-27. https://doi.org/10.1016/j.comppsych.2019.03.003

Kardefelt-Winther, D. (2014). A conceptual and methodological critique of internet addiction research: Towards a model of compensatory internet use. Computers in Human Behavior, 31, 351-354. https://doi.org/10.1016/j.chb.2013.10.059

Király, O., Potenza, M. N., Stein, D. J., King, D. L., Hodgins, D. C., Saunders, J. B., ... \& Abbott, M. W. (2020). Preventing problematic internet use during the COVID-19 pandemic: $\begin{array}{lll}\text { Consensus } \quad \text { guidance. Comprehensive } & 152180 .\end{array}$ https://doi.org/10.1016/j.comppsych.2020.152180

Kircaburun, K., Alhabash, S., Tosuntaş, Ș. B., \& Griffiths, M. D. (2020). Uses and gratifications of problematic social media use among university students: A simultaneous examination of the Big Five of personality traits, social media platforms, and social media use motives. International Journal of Mental Health and Addiction, 18(3), 525-547.

König, R., Seifert, A., and Doh, M. (2018). Internet use among older Europeans: an analysis based on SHARE data. Univ. Access Inf. Soc., 17, 621-633. https://doi.org/10.1007/s10209-018$\underline{0609-5}$

Krasnova, H., Veltri, N. F., Eling, N., \&Buxmann, P. (2017). Why men and women continue to use social networking sites: The role of gender differences. The Journal of Strategic Information Systems, 26(4), 261-284. https://doi.org/10.1016/j.jsis.2017.01.004

Kuss, D. J., \& Lopez-Fernandez, O. (2016). Internet addiction and problematic Internet use: A systematic review of clinical research. World journal of psychiatry, 6(1), 143-176. https://doi.org/10.5498/wjp.v6.i1.143

Laconi, S., Kaliszewska-Czeremska, K., Gnisci, A., Sergi, I., Barke, A., Jeromin, F., ... \&Király, O. (2018). Cross-cultural study of Problematic Internet Use in nine European countries. Computers in Human Behavior, 84, 430-440. https://doi.org/10.1016/j.chb.2018.03.020

LaRose, R., \& Eastin, M.S. (2004). A social cognitive theory of Internet uses and gratifications: toward a new model of media attendance. Journal of Broadcasting \& Electronic Media, 48(3): 358-377. Doi:10.1207/s15506878jobem4803 2

Li, S. M., \& Chung, T. M. (2006). Internet function and Internet addictive behavior. Computers in Human Behavior, 22(6), 1067-1071.https://doi.org/10.1016/j.chb.2004.03.030

Lim, H., \& Kumar, A. (2019). Variations in consumers' use of brand online social networking: A uses and gratifications approach. Journal of Retailing and Consumer Services, 51, 450-457. https://doi.org/10.1016/j.jretconser.2017.10.015 
${ }^{1}$ Liu, D., Ren, Y., Yan, F., Li, Y., Xu, X., Yu, ... Tan, S. (2020). Psychological Impact and Predisposing Factors of the Coronavirus Disease 2019 (COVID-19) Pandemic on General

Public in China. Lancet Psychiatry. Retrieved 20th of July, 2020 fromhttps://papers.ssrn.com/sol3/papers.cfm?abstract_id=3551415.https://doi.org/10.2139/ssr $\underline{\text { n.3551415 }}$

Loades, M. E., Chatburn, E., Higson-Sweeney, N., Reynolds, S., Shafran, R., Brigden, A., ... \& Crawley, E. (2010). Rapid Systematic Review: The Impact of Social Isolation and Loneliness on the Mental Health of Children and Adolescents in the Context of COVID-19. Journal of the American Academy of Child \& Adolescent Psychiatry, available online 2 September 2020.https://doi.org/10.1016/j.jaac.2020.05.009

Lopez-Fernandez, O., Griffiths, M. D., Kuss, D. J., Dawes, C., Pontes, H. M., Justice, L., ... \&Männikkö, N. (2019). Cross-cultural validation of the Compulsive Internet Use Scale in four forms and eight languages. Cyberpsychology, Behavior, and Social Networking, 22(7), 451-464. https://doi.org/10.1089/cyber.2018.0731

Lupton, D., \& Maslen, S. (2019). How women use digital technologies for health: qualitative interview and focus group study. Journal of medical Internet research, 21(1), e11481. Doi: $10.2196 / 11481$

Mak, I. W. C., Chu, C. M., Pan, P. C., Yiu, M. G. C., \& Chan, V. L. (2009). Long-term psychiatric morbidities among SARS survivors. General hospital psychiatry,31(4), 318-326. Doi:10.1016/j.genhosppsych.2009.03.001

Marino, C., Finos, L., Vieno, A., Lenzi, M., \& Spada, M. M. (2017). Objective Facebook behaviour: Differences between problematic and non-problematic users. Computers in Human Behavior, 73, 541-546. https://doi.org/10.1016/j.chb.2017.04.015

Marino, C., Gini, G., Vieno, A., \& Spada, M. M. (2018b). A comprehensive meta-analysis on problematic Facebook use. Computers in Human Behavior, 83, 262-277. https://doi.org/10.1016/j.chb.2018.02.009

Marino, C., Mazzieri, E., Caselli, G., Vieno, A., \& Spada, M. M. (2018). Motives to use Facebook and problematic Facebook use in adolescents. Journal of Behavioral Addictions, 7(2), 276283. https://doi.org/10.1556/2006.7.2018.32

McPherson, K. E., Kerr, S., Morgan, A., McGee, E., Cheater, F. M., McLean, J., \& Egan, J. (2013). The association between family and community social capital and health risk behaviours in young people: An integrative review. BMC Public Health, 13, 971. https://doi.org/10.1186/1471-2458-13-971

Mohseni, M., Dowran, B., \&SohrabiHaghighat, M. H. (2008). Does the Internet Make People Socially Isolated? A Social Network Approach. Bangladesh e-Journal of Sociology, 5(1), 113.

Montemurro, N. (2020). The emotional impact of COVID-19: From medical staff to common people. Brain, behavior, and immunity, 87, 23-24. https://doi.org/10.1016/i.bbi.2020.03.03

Musetti, A., Corsano, P., Boursier, V., \&Schimmenti, A. (2020). Problematic internet use in lonely adolescents: the mediating role of detachment from parents. Clinical Neuropsychiatry, 17(1), 3-10.https://doi.org/10.36131/clinicalnpsych2020010

Muusses, L. D., Finkenauer, C., Kerkhof, P., \&Billedo, C. J. (2014). A longitudinal study of the association between compulsive internet use and wellbeing. Computers in Human Behavior, 36, 21-28. https://doi.org/10.1016/j.chb.2014.03.035

Nabi, R. L., Prestin, A., \& So, J. (2013). Facebook friends with (health) benefits? Exploring social network site use and perceptions of social support, stress, and well-being. Cyberpsychology, Behavior, and Social Networking, 16(10), 721-727. https://doi.org/10.1089/cyber.2012.0521

Nie, N. H. (2001). Sociability, interpersonal relations, and the Internet: Reconciling conflicting findings. American Behavioral Scientist, 45, 419-435. https://doi.org/10.1177/00027640121957277 
Nowland, R., Necka, E. A., \& Cacioppo, J. T. (2018). Loneliness and social internet use: pathways to reconnection in a digital world?Perspectives on Psychological Science, 13(1), 70-87. https://doi.org/10.1177/1745691617713052

Ohno, S. (2016). Internet escapism and addiction among Japanese senior high school students. International Journal of Culture and Mental Health, 9(4), 399-406. https://doi.org/10.1080/17542863.2016.1226911

Papacharissi, Z., \& Mendelson, A. (2010). 12 Toward a new (er) sociability: uses, gratifications and social capital on Facebook. In S. Papathanassopoulos (Ed.) Media perspectives for the 21st century (pp. 212-230). Routledge.

Pearce, K. E., \& Rice, R. E. (2013). Digital divides from access to activities: Comparing mobile and personal computer Internet users. Journal of communication, 63(4), 721744.https://doi.org/10.1111/jcom.12045

Poortinga, W. (2006). Social relations or social capital? Individual and community health effects of bonding social capital. Social science \& medicine, 63(1), 255-270. https://doi.org/10.1016/j.socscimed.2005.11.039

R Core Team (2013). R: A language and environment for statistical computing [Computer software manual]. Vienna, Austria. Retrieved 20th of July 2020 from: http://www.R-project.org/.

Rinaldi, A. (2020). Donne e uomini, perché con la pandemiasirischia un passoindietro (Women and men, why with the pandemic there is the risk of a step back). Il Sole 24 ore. Retrieved 20th of July 2020 from:https://www.econopoly.ilsole24ore.com/2020/04/23/parita-donne-pandemia/

Rosseel, Y. (2012). Lavaan: An R package for structural equation modeling. Journal of Statistical Software, 48, 1-36.

Ruggieri, S., Santoro, G., Pace, U., Passanisi, A., \&Schimmenti, A. (2020). Problematic Facebook use and anxiety concerning use of social media in mothers and their offspring: An actorpartner interdependence model. Addictive Behaviors Reports, 11, 100256. https://doi.org/10.1016/j.abrep.2020.100256

Saltzman, L. Y., Hansel, T. C., \&Bordnick, P. S. (2020). Loneliness, isolation, and social support factors in post-COVID-19 mental health. Psychological trauma: theory, research, practice and policy, 12(S1), S55-S57.https://doi.org/10.1037/tra0000703

Saltzman, L. Y., Hansel, T. C., \&Bordnick, P. S. (2020). Loneliness, isolation, and social support factors in post-COVID-19 mental health. Psychological trauma: theory, research, practice and policy, 12 (1), 55-57.https://doi.org/10.1037/tra0000703

Schimmenti A., Starcevic V., Giardina A., Khazaal Y., Billieux J. (2020). Multidimensional assessment of COVID-19-related fears (MAC-RF): A theory-based instrument for the assessment of clinically relevant fears during pandemics. Frontiers in Psychiatry. 11:748. https://doi.org/10.3389/fpsyt.2020.00748

Schimmenti, A.,\&Caretti, V. (2010). Psychic retreats or psychic pits? Unbearable states of mind and technological addiction. Psychoanalytic Psychology,27(2), 115-132. https://doi.org/10.1037/a0019414.

Schimmenti, A., \& Caretti, C. (2017). Video-terminal dissociative trance: Toward a psychodynamic understanding of problematic Internet use. Clinical Neuropsychiatry, 14 (1), 64-72.

Schimmenti, A., Billieux, J., \&Starcevic, V. (2020). The four horsemen of fear: An integrated model of understanding fear experiences during the COVID-19 pandemic. ClinicalNeuropsychiatry, 17(2), 41-45.https://doi.org/10.36131/CN20200202

Schimmenti, A., Guglielmucci, F., Barbasio, C., \& Granieri, A. (2012). Attachment disorganization and dissociation in virtual worlds: a study on problematic internet use among players of online role playing games. Clinical Neuropsychiatry, 9, 195-202.

Seifert, A. (2020). The digital exclusion of older adults during the COVID-19 pandemic. Journal of Gerontological Social Work, 1-3. https://doi.org/10.1080/01634372.2020.1764687 
Selwyn, N., Gorard, S., \& Furlong, J. (2005). Whose Internet is it anyway? Exploring adults'(non) use of the Internet in everyday life. European Journal of Communication, 20(1), 526.https://doi.org/10.1177/0267323105049631

Sharifpoor, E., Khademi, M. J., \&Mohammadzadeh, A. (2017). Relationship of internet addiction with loneliness and depression among high school students. Int. J. Psychol. Behav. Sci. 7, 99102.

Smith, M.L., Steinman, L.E., \& Casey, E.A. (2020). Combatting Social Isolation Among Older Adults in a Time of Physical Distancing: The COVID-19 Social Connectivity Paradox. Frontiers in Public Health, 8, 403. https://doi.org/10.3389/fpubh.2020.00403

Song, H., Zmyslinski-Seelig, A., Kim, J., Drent, A., Victor, A., Omori, K., \& Allen, M. (2014). Does Facebook make you lonely?:Ameta analysis. Comput. Hum. Behav. 36, 446-452. https://doi.org/10.1016/j.chb.2014.04.011

Sood, S. (2020). Psychological effects of the Coronavirus disease-2019 pandemic. Research \& $\begin{array}{llll}\text { Humanities in } & \text { Edical 23-26. }\end{array}$ https://www.rhime.in/ojs/index.php/rhime/article/view/264

Tang, J. H., Chen, M. C., Yang, C. Y., Chung, T. Y., \& Lee, Y. A. (2016). Personality traits, interpersonal relationships, online social support, and Facebook addiction. Telematics and Informatics, 33(1), 102-108. https://doi.org/10.1016/i.tele.2015.06.003

Tian, Y., Bian, Y. L., Han, P. G., Gao, F. Q., and Wang, P. (2017). Associations between psychosocial factors and generalized pathological internet use in Chinese university students: a longitudinal cross-lagged analysis. Comput. Hum. Behav. 72, 178-188. https://doi.org/10.1016/j.chb.2017.02.048

Venkatesh, V., Thong, J.Y. X., Xu, X. (2012). Consumer acceptance and use of information technology: extending the unified theory of acceptance and use of technology. Manag. Inf. Syst. Q., 36 (1), 157-178.https://doi.org/10.2307/41410412

Van den Eijnden, R. J., Meerkerk, G. J., Vermulst, A. A., Spijkerman, R., \& Engels, R. C. (2008). Online communication, compulsive Internet use, and psychosocial well-being among adolescents: $\quad$ A longitudinal study. Developmental psychology, 44(3), 655. https://doi.org/10.1037/0012-1649.44.3.655

Van Deursen, A., \& Van Dijk, J. (2014). The digital divide shifts to differences in usage. NewMedia \& Society, 16(3), 507-526. https://doi.org/10.1177/1461444813487959

Venuleo, C., Gelo, C. G. O., \& Salvatore, S. (2020). Fear, affective semiosis, and management of the pandemic crisis: COVID-19 as semiotic vaccine? Clinical Neuropsychiatry, 17(2), 117130. https://doi.org/10.36131/CN20200218

Venuleo, C., Marinaci, T., Gennaro, A., Palmieri, A. (2020). The meaning of living in the time of COVID-19. A large sample narrative inquiry. Frontiers in Psychology, 11: 577077. Doi:10.3389/fpsyg. 2020.577077

Venuleo, C., Rollo, S., Marinaci, T., \& Calogiuri, S. (2016). Towards a cultural understanding of addictive behaviours: The image of the social environment among problem gamblers, drinkers, internet users and smokers. Addiction Research \& Theory, 24, 274-287. https://doi.org/10.3109/16066359.2015.1126257

Vidal, C., Lhaksampa, T., Miller, L., \& Platt, R. (2020). Social media use and depression in adolescents: a scoping review. International Review of Psychiatry, 32(3), 235-253. https://doi.org/10.1080/09540261.2020.1720623

Vijayaraghavan, P., \& Singhal, D. (2020). A Descriptive Study of Indian General Public's Psychological responses during COVID-19 Pandemic Lockdown Period in India. PsyArXiv. https://doi.org/10.31234/osf.io/jeksn

Wang, E. S. T., \& Wang, M. C. H. (2013). Social support and social interaction ties on internet addiction: Integrating online and offline contexts. Cyberpsychology, Behavior, and Social Networking, 16(11), 843-849. https://doi.org/10.1089/cyber.2012.0557 
Wang, J., Mann, F., Lloyd-Evans, B., Ma, R., ～\& Johnson, S. (2018). Associations $\quad$ between loneliness and perceived social support and outcomes of mental health problems: A systematic review. BMC Psychiatry, 18, Article 156. https://doi.org/10.1186/s12888-018$1736-5$

Wartberg, L., Zieglmeier, M., \&Kammerl, R. (2020). An Empirical Exploration of Longitudinal Predictors for Problematic Internet Use and Problematic Gaming Behavior. Psychological Reports, 0033294120913488. https://doi.org/10.1177/0033294120913488

Weiser, E. B. (2000). Gender differences in Internet use patterns and Internet application preferences: A two-sample comparison. Cyberpsychology and behavior, 3(2), 167-178. https://doi.org/10.1089/109493100316012

Yao, M. Z., \& Zhong, Z. J. (2014). Loneliness, social contacts and Internet addiction: A crosslagged panel study. Computers in Human Behavior, 30, 164-170. https://doi.org/10.1016/i.chb.2013.08.007

Yu, L., Recker, M., Chen, S., Zhao, N., \& Yang, Q. (2018). The moderating effect of geographic area on the relationship between age, gender, and information and communication technology literacy and problematic internet use. Cyberpsychology, Behavior, and Social Networking, 21(6), 367-373. https://doi.org/10.1089/cyber.2017.0503

Zammuner, V. L. (2008). Italians' social and emotional loneliness: The results of five studies. International Journal of Social Sciences, 3(2), 108-120.

Zhang, S., Tian, Y., Sui, Y., Zhang, D., Shi, J., Wang, P., ... \& Si, Y. (2018). Relationships between social support, loneliness, and internet addiction in Chinese postsecondary students: a longitudinal cross-lagged analysis. Frontiers in psychology, 9, 1707. https://doi.org/10.3389/fpsyg.2018.01707

Zimmermann, M., Bledsoe, C., \& Papa, A. (2020). The Impact of the COVID-19 Pandemic on College Student Mental Health: A Longitudinal Examination of Risk and Protective Factors.PsyArXiv. https://doi.org/10.31234/osf.io/2y7hu

Zywica, J., \& Danowski, J. (2008). The faces of Facebookers: Investigating social enhancement and social compensation hypotheses; predicting Facebook ${ }^{\mathrm{TM}}$ and offline popularity from sociability and self-esteem, and mapping the meanings of popularity with semantic networks. Journal of Computer-Mediated Communication, 14(1), 1-34. https://doi.org/10.1111/j.1083-6101.2008.01429.x

Venuleo, C., Ferrante, L., \& Rollo, S. (2020).Facing life problems through the internet. The link between psychosocial malaise and problematic Internet use in an adolescent sample. Journal of gambling issues.

Wiederhold, B.K. (2020). Using social media to our advantage: alleviating anxiety during a pandemic. Cyberpsychology, Behavior, and Social Networking, 23(4), 197-198. https://doi.org/10.1089/cyber.2020.29180.bkw 
Figure 1. Results of the multivariate multiple regression analysis

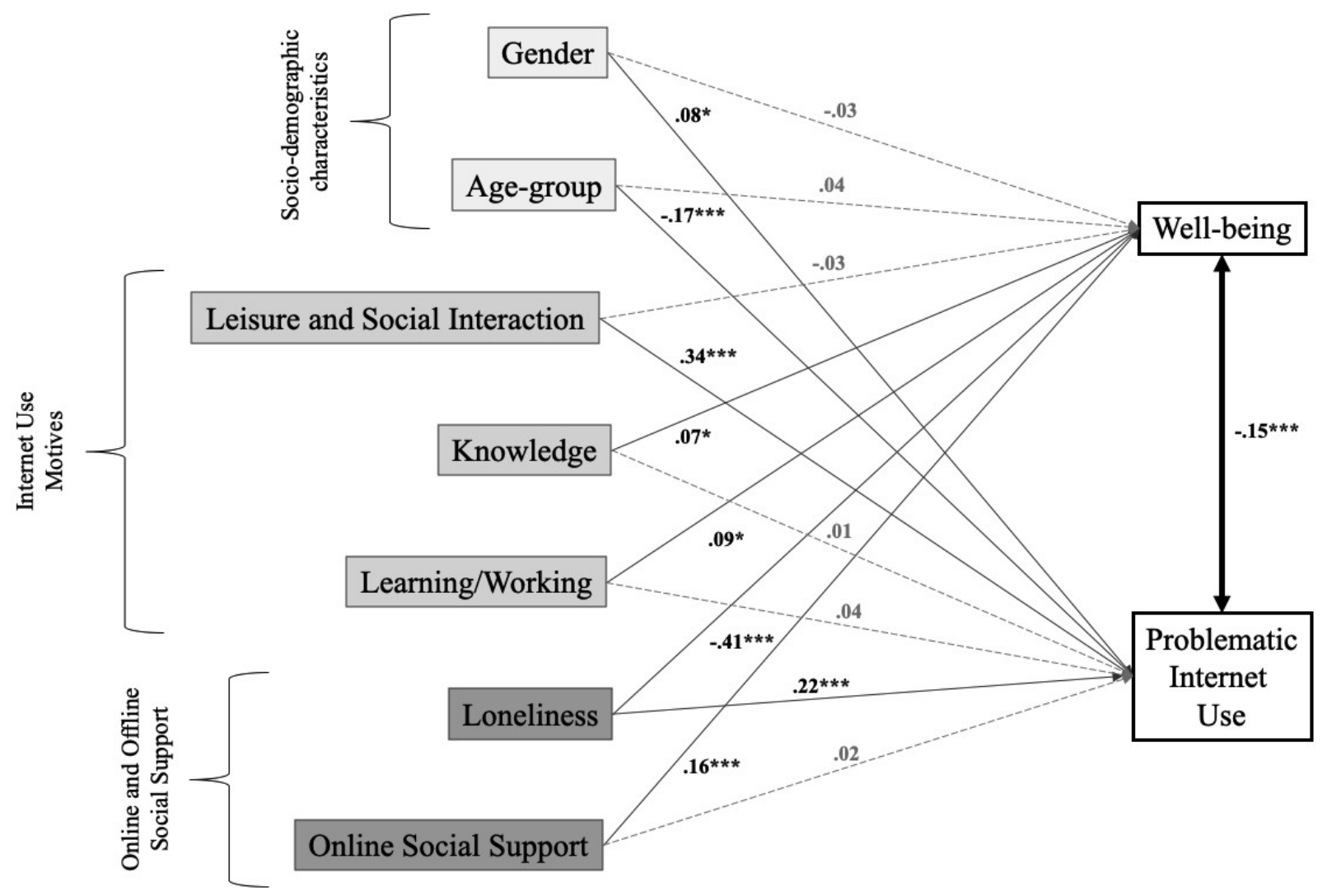

Notes: $* p<.05 ; * * p<.01 ; * * * p<.001$. 


\section{Table 1 - Components of internet use motives (PCA)}

\begin{tabular}{|c|c|c|c|c|}
\hline \multirow{2}{*}{$\begin{array}{l}\text { Items } \\
\text { In the last two weeks, how much } \\
\text { have you used the Internet... }\end{array}$} & \multicolumn{3}{|c|}{ Factor loadings } & \multirow[t]{2}{*}{ Components' label } \\
\hline & 1 & 2 & 3 & \\
\hline ...to have fun/to spend time & .81 & & -.13 & \\
\hline ...to escape from reality & .76 & & & \\
\hline $\begin{array}{l}\text {...to satisfy interpersonal and social } \\
\text { needs }\end{array}$ & .67 & .27 & .23 & $\begin{array}{l}\text { Leisure and social interaction } \\
\text { purposes }\end{array}$ \\
\hline $\begin{array}{l}\text {...to maintain connections with the } \\
\text { loved ones }\end{array}$ & .60 & .40 & .24 & \\
\hline $\begin{array}{l}\text {... to acquire information on the } \\
\text { COVID-19 health emergency }\end{array}$ & & .78 & & \\
\hline .... to have cultural entertainment to & & & & Knowledge purposes \\
\hline $\begin{array}{l}\text { visit museum online, to read books } \\
\text { online...) }\end{array}$ & .14 & .71 & & \\
\hline
\end{tabular}


Table 2 - Mean and Standard Deviation of Internet use motives for gender and age-group

\begin{tabular}{|c|c|c|c|c|c|c|c|c|c|c|}
\hline \multirow{2}{*}{\multicolumn{2}{|c|}{ Demographic variables }} & \multicolumn{3}{|c|}{ Leisure and social interaction purposes } & \multicolumn{3}{|c|}{ Knowledge purposes } & \multicolumn{3}{|c|}{ Learning/working purposes } \\
\hline & & \multicolumn{2}{|c|}{ Mean (SD) } & $\mathrm{F}$ & \multicolumn{2}{|c|}{ Mean (SD) } & \multirow{3}{*}{$\frac{\mathrm{F}}{3.99^{*}}$} & \multicolumn{2}{|c|}{ Mean (SD) } & \multirow{3}{*}{$\frac{\mathrm{F}}{9.11^{* *}}$} \\
\hline Gender & Men & -0.15 & $(0.92)$ & $663 *$ & -0.11 & $(1.01)$ & & -0.16 & $(1.00)$ & \\
\hline Ginder & Women & 0.07 & $(1.03)$ & & 0.07 & $(0.99)$ & & 0.10 & $(0.98)$ & \\
\hline \multirow{4}{*}{ Age-group } & $18-25$ & 0.38 & $(0.98)$ & \multirow{4}{*}{$30.60^{* * *}$} & -0.25 & $(1.08)$ & \multirow{4}{*}{$7.09 * * *$} & 0.08 & $(0.88)$ & \multirow{4}{*}{$5.82 * *$} \\
\hline & $26-35$ & 0.35 & $(0.96)$ & & 0.03 & $(0.87)$ & & 0.09 & $(0.91)$ & \\
\hline & $36-45$ & -0.10 & $(1.00)$ & & 0.40 & $(0.84)$ & & 0.34 & $(0.87)$ & \\
\hline & $45+$ & -0.42 & $(0.86)$ & & 0.07 & $(0.99)$ & & -0.19 & (1.11) & \\
\hline
\end{tabular}

$\frac{45+\quad-0.42}{\text { Notes: }{ }^{*} p<.05 ; * * p<.01 ; * * *} p<.001$ 
Table 3 - Internet use motives and relational resources - Pearson's correlations

\begin{tabular}{lccc}
\hline Internet Use Motives & $\begin{array}{c}\text { Leisure and social } \\
\text { interaction }\end{array}$ & Knowledge & Learning/working \\
\hline Gender & $.11^{*}$ & $.08^{*}$ & $.13^{* *}$ \\
Age & $-.37^{* * *}$ & $.10^{*}$ & $-.19^{* * *}$ \\
\hline Loneliness & $.12^{* *}$ & -.08 & -.07 \\
Online Support & $.30^{* *}$ & $.17^{* *}$ & $.14^{* *}$ \\
Problematic Internet Use & $.45^{* * *}$ & -.02 & .06
\end{tabular}

Problematic Internet Use $\quad .45^{* * *}$ 
Availability of data and material: The raw data supporting the conclusions of this article will be made available by the authors, without undue reservation

Conflicts of interest/Competing interests: Authors have no affiliation with or financial interest in any organization that might pose a conflict of interest.

Ethics approval: the project was approved by the Ethics Commission for Research in Psychology of the Department of History, Society and Human Studies of the University of Salento (protocol n. 53162 of 30 April 2020).

Consent to participate: The participants provided their written informed consent to participate in this study. 
Figures

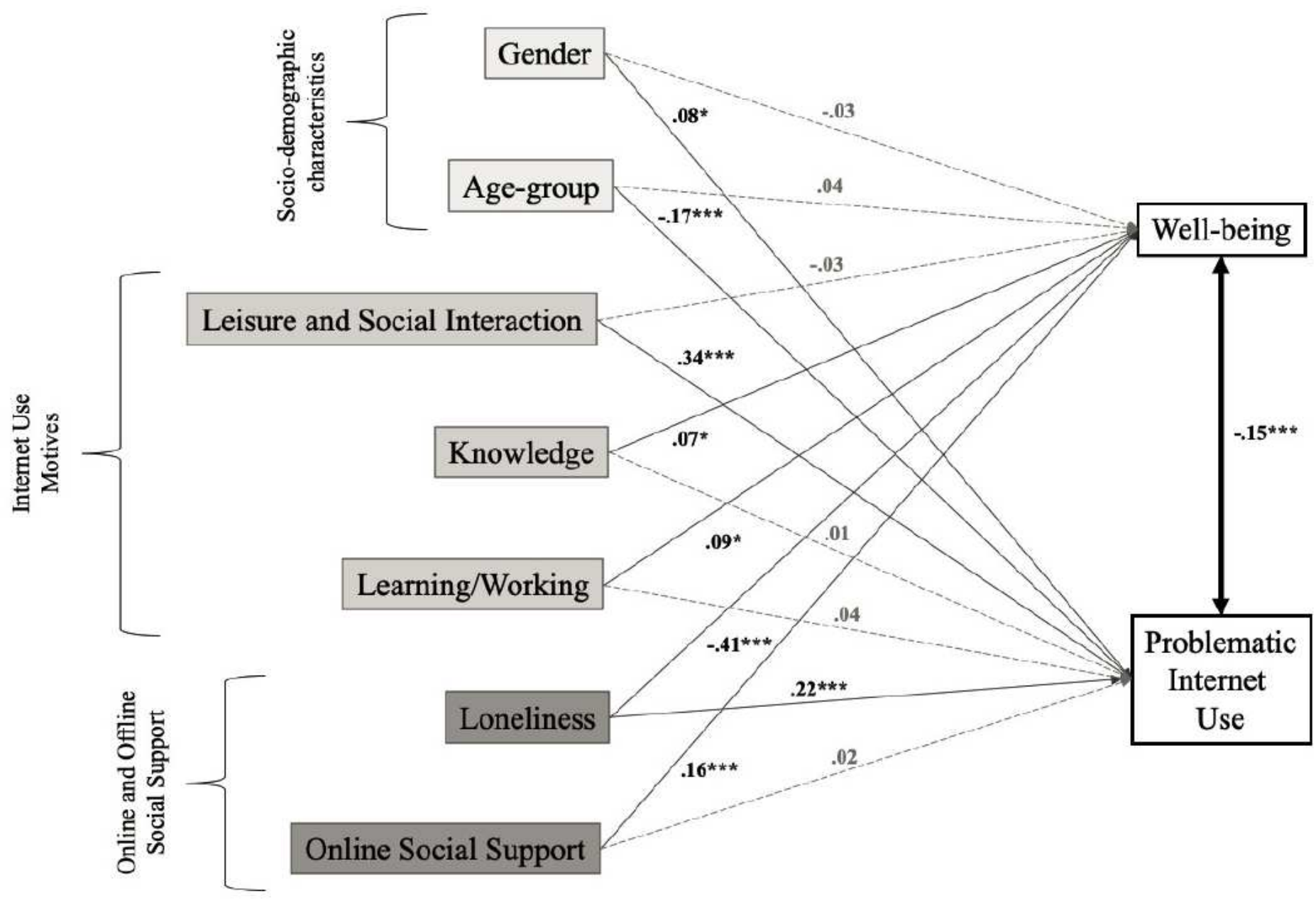

Figure 1

Results of the multivariate multiple regression analysis. Notes: ${ }^{\star} p<.05 ; * \star p<.01 ; * \star \star ~ p<.001$. 